\title{
Severe Acute Cytomegalovirus Infection Complicated by Disseminated Intravascular Coagulation and Pneumonitis in a Healthy Female
}

Zain Chagla MD, Deborah Siegal MD, Phillippe El-Helou MD, Wendy Lim MD, Jill Rudkowski MD

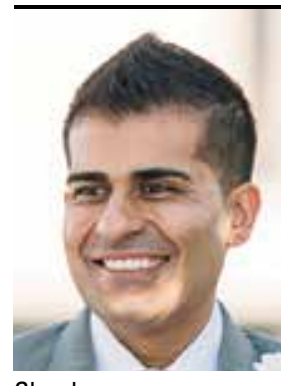

Chagla

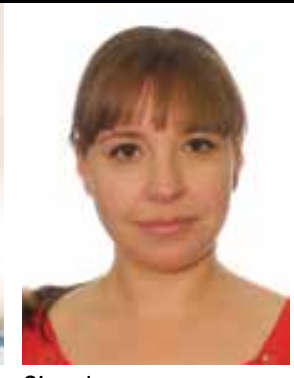

Siegal

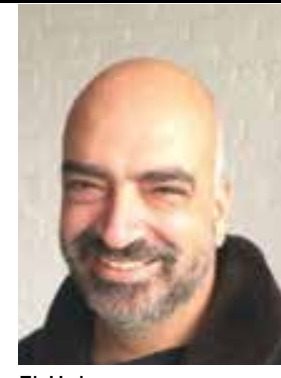

El-Helou

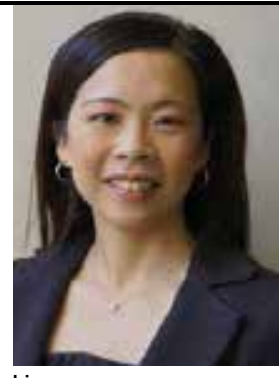

Lim

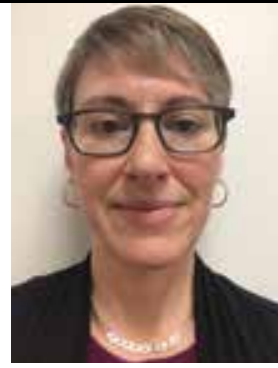

Rudkowski

\section{About the Authors}

Zain Chagla is an Assistant Professor of in the Department of Medicine at McMaster University. Deborah Siegal is a Clinical Scholar in the Department of Hematology and Thromboembolism at McMaster University. Phillippe El-Helou is an Associate Professor in the Department of Medicine at McMaster University. Wendy Lim is an Associate Professor in the Department of Medicine at McMaster University. Jill Rudkowski is an Associate Professor in the Department of Medicine at McMaster University. Correspondence may be directed to chaglaz@mcmaster.ca.

\begin{abstract}
Cytomegalovirus (CMV) is an endemic infection worldwide. Among healthy individuals, infections are usually asymptomatic. An infectious mononucleosis-type syndrome is classically described. More serious manifestations, such as pneumonitis, hepatitis, and meningoencephalitis have been described in otherwise healthy populations. Disseminated intravascular coagulation is a life-threatening complication that is extremely rare in competent hosts. We describe a case of pneumonitis and DIC associated with acute CMV infection that resolved with antiviral therapy.
\end{abstract}

\section{Résumé}

Les infections à cytomégalovirus (CMV) sont présentes de façon endémique partout dans le monde. Chez les individus en bonne santé, l'infection est habituellement asymptomatique. Sa présentation classique est celle d'un syndrome infectieux de type mononucléosique. Certaines manifestations plus sérieuses, comme la pneumonie, l'hépatite et la méningoencéphalite sont toutefois signalées dans des populations par ailleurs en santé. La coagulation intravasculaire disséminée (C.I.D.) en est une complication délétère extrêmement rare observée chez certains sujets. Nous décrivons ici un cas de pneumonite et de C.I.D. associé à une CMV aiguë qui fut guéri par l'administration d'agents antiviraux. 


\section{Case Report}

A 39-year-old African-Canadian female presented to the emergency room for assessment of a nonspecific febrile illness. Her past medical history was significant for celiac disease. She was compliant to her diet. She had a 25-pack/year smoking history. She was on no medications and had no allergies. She reported one sexual partner without condom use, but no history of sexually transmitted infections. A family member in her household had a recent, self-resolving, flu-like illness. She denied recent travel, intravenous or illicit drug use, or alcohol abuse. She had one healthy pet dog at home.

The patient initially presented with fevers, chills, and sweats of 10 days duration. This was associated with exertional dyspnea, a non-productive cough, nausea, vomiting, myalgias, intermittent abdominal pain, and mild diarrhea. On examination in the emergency room, her temperature was 38.3 degrees Celsius, blood pressure 106/70 $\mathrm{mmHg}$, pulse 105 beats/minute, respiratory rate $20 /$ minute, pulse oximetry $92 \%$ on 3 liters of oxygen by nasal prongs. Her abdomen was tender to palpation in all 4 quadrants, with no peritoneal signs. Her pulmonary examination revealed decreased breath sounds and inspiratory crackles in the right lower lung zone on auscultation. The rest of her examination was unremarkable.

Her initial complete blood count revealed anemia (hemoglobin $105 \mathrm{~g} / \mathrm{L}$, normal 115-165 g/L), thrombocytopenia ( $107 \times 10^{9}$ cells/L, normal $150-450 \times 10^{9}$ cells/L), and leukocytosis (leukocyte count of $26.6 \times 10^{9}$ cells/L, normal $4-11 \times 10^{9}$ cells/L) with lymphocytosis $\left(11.9 \times 10^{9}\right.$ cells/L, normal $1.5-4.0 \times 10^{9}$ cells/L) and monocytosis $\left(3.2 \times 10^{9}\right.$ cells/L, normal $0.2-0.8 \times 10^{9}$ cells/L). A blood film showed atypical lymphocytosis. There was evidence of coagulopathy with elevated international normalized ratio and partial thromboplastin time at 1.7 (normal $0.8-1.2$ ) and 59 seconds (normal 22-35 seconds), respectively. Fibrinogen was low at $0.6 \mathrm{~g} / \mathrm{L}$ (normal 1.6$4.2 \mathrm{~g} / \mathrm{L}$ ), and a coombs test was negative. Her C-reactive protein was $19.4 \mathrm{mg} / \mathrm{L}$ (normal $<=5.0 \mathrm{mg} / \mathrm{L}$ ). Her alanine aminotransferase was elevated at $56 \mathrm{U} / \mathrm{L}$ (normal $<=28 \mathrm{U} / \mathrm{L}$ ). Lactate dehydrogenase was $1041 \mathrm{U} / \mathrm{L}$ (normal 100-220 U/L). The remainder of her electrolytes and chemistry were within normal limits. A chest radiograph revealed a right lower lobe infiltrate. Computerized tomography (CT) of the abdomen revealed resolving non-specific colitis in the sigmoid and rectum with a diagnostic consideration of inflammatory bowel disease or infectious colitis.

An extensive infectious workup including blood and sputum bacterial cultures, Epstein-Barr Virus (EBV) serology, and Human Immunodeficiency Virus (HIV) enzyme-linked immunosorbent assay (ELISA) and p24 antigen were negative.
The patient had detectable cytomegalovirus (CMV) IgG and IgM serology and strongly positive CMV polymerase chain reaction (PCR) from serum $\left(5.5 \log _{10}\right.$ copies $/ \mathrm{mL}$, normal undetectable). Given the atypical lymphocytosis and the concern of a malignant hematologic process, flow cytometry was performed revealed a predominant CD8 population without evidence of clonality, in keeping with an inflammatory process.

Two days after admission, she developed hypoxic respiratory failure requiring endotracheal intubation. Her coagulopathy worsened with evidence of schistocytosis on repeated blood smears, and she was treated with fresh frozen plasma and cryoprecipitate. Her hepatic transaminases and LDH remained elevated but stable. A bronchoalvelolar lavage specimen was positive for CMV by PCR testing (4.67 $\log _{10}$ copies/mL, normal undetectable) without evidence of other bacterial, viral, or fungal organisms. A CT scan of the chest revealed bilateral mediastinal adenopathy, central and upper lobe predominant ground glass opacities, without evidence of pulmonary embolism, in keeping with a viral pneumonitis, and no evidence of specific lobar infiltrate.

Given the severity and organ dysfunction from her underlying viremia, the patient was started on gancyclovir at $5 \mathrm{mg} / \mathrm{kg}$ every 12 hours for 2 weeks. She also empirically received a pulse dose of 1 gram of methylprednisolone because of impending respiratory demise. She improved rapidly over the next 2 days with resolution of her respiratory failure, disseminated intravascular coagulation (DIC), hepatic transaminases, LDH, and atypical lymphocytosis. Repeat CMV PCR after 2 weeks was entirely negative. The patient was discharged home on day 14 without further therapy, and at 1-month follow-up was back to baseline function.

\section{Discussion}

Cytomegalovirus, a member of a $B$ herpesviridae family, is an endemic infection worldwide. Seroprevalence studies in the United States have shown rates up to $50.4 \%$, with socioeconomic status and ethnicity tied to higher rates. ${ }^{1}$ Among those infected, most are asymptomatic or have self-limited illnesses. However, acute infection in the immunocompromised, as well as viral latency and reactivation, cause a significant burden of disease. Severe manifestations may be seen among bone marrow and solid organ transplant patients, those on chronic glucocorticoids and/or other immunosuppressants, and those with HIV infection. ${ }^{2}$

A number of manifestations can be seen in immunocompetent individuals. While most infections are asymptomatic, an infectious mononucleosis-type syndrome 
is classically described and acute CMV infection can mimic acute EBV infection. More serious manifestations, such as pneumonitis, hepatitis, and meningoencephalitis have been described in otherwise healthy populations. ${ }^{2}$ Severe disease in immunocompetent individuals is rare, although significant morbidity and mortality has been described. A recent case series reviewed 290 patients with severe disease. Manifestations included the gastrointestinal tract, portal vein thrombosis, meningoencephalitis, pneumonitis, hepatitis, myocarditis, pericarditis, and ocular manifestations such as retinitis. Hematologic manifestations such as thrombocytopenia and hemolytic anemia were also described. ${ }^{3}$

The hallmark finding in this patient was the presence of reactive lymphocytosis. A differential diagnosis includes infections, acute physiologic stress, hypersensitivity (Drug Reaction with Eosinophila and Systemic Symptoms), and malignancy. Although CMV and EBV are common causes, acute infections such as HIV, Herpes Simplex Virus II, Rubella, Toxoplasma gondii, Adenovirus, Dengue, Human Herpes Virus 6 and 8, Varicella Zoster Virus, and Bordatella pertussis have been associated with reactive lymphocytosis. Other chronic infections such as Leishmaniasis, Leprosy, and Strongyloidiasis have also been described. ${ }^{4}$ Clinicians encountering atypical lymphocytosis on blood smear should consider a broad differential diagnosis and consider serologic testing based on clinical symptoms.

The development of DIC in this otherwise immunocompetent patient was a potentially life-threatening complication of her viremia. DIC is a known consequence of CMV among immunocompromised hosts, however, only two previous healthy patients developing DIC with documented acute CMV infection have been reported in the literature. A 63-year-old healthy female, who was diagnosed based on IgM and IgG, presented with severe DIC and acute respiratory distress syndrome (ARDS), and was subsequently treated with plasmapheresis alone with clinical response. ${ }^{5}$ Another pediatric patient did not respond to supportive management and ultimately died. ${ }^{6}$ The mechanism of DIC may be related to viral pathogenesis. Rat models of CMV indicate the presence of extensive vascular and endothelial damage and demonstrate hematologic parameters compatible with DIC. ${ }^{7}$ In vitro CMV infection of human umbilical vein endothelial cells causes a procoagulant response more rapid than the tissue factor response through the usual inflammatory pathway. ${ }^{8}$

The use of antiviral therapy and corticosteroids in our patient was based on the deterioration in her clinical status. However, it is unclear whether antiviral therapy alters the natural history of disease or complications. Furthermore, the potential toxicity associated with treatment must be weighed against the benefit, particularly in those who present with mild to moderate manifestations. Orasch and Conen describe 3 immunocompetent patients with multiorgan dysfunction treated with antiviral therapy ${ }^{9}$ with clinical improvement and discharge from hospital. In another review of healthy patients with severe disease, 6 of 7 patients $(85.7 \%)$ treated with CMV specific antiviral therapy survived. Of the untreated patients, 13 of 27 (48.1\%) survived..$^{10}$ Therapies described in the literature include gancyclovir, valgancyclovir, and foscarnet, ${ }^{3}$ although the ideal dose, parameters for monitoring therapeutic response, and need for induction and maintenance therapy are unknown.

In conclusion, this case of primary cytomegalovirus infection in an immunocompetent female complicated by DIC and pneumonitis causing respiratory failure demonstrated clinical and microbiologic response following treatment with gancyclovir. Given the seroprevalence of this infection in the general population, clinicians should consider this diagnosis in unexplained viral syndromes, particularly with hematologic abnormalities.

\section{References}

1. Bate S, Dollard S, Cannon M. Cytomegalovirus seroprevalence in the United States: the national health and nutrition examination surveys, 1988-2004. Clin Infect Dis 2010;50(11):1439-47.

2. Crumpacker C, Zhang J. Cytomegalovirus. In: Mandell GL, Bennett, JE, \& Dolin R, editors. Principles and Practice of Infectious Diseases. $7^{\text {th }}$ ed. Philadelphia, PA: Churchill Livingston; 2009. p. 1971-87.

3. Rafailidis P, Mourtzoukou E, Varbobitis I, et al. Severe cytomegalovirus infection in apparently immunocompetent patients: a systematic review. Virol J 2008; 27(5):47.

4. Kipps TJ. Chapter 81. Lymphocytosis and Lymphocytopenia. In: Prchal JT, Kaushansky K, Lichtman MA, Kipps TJ, Seligsohn U, eds. Williams Hematology. 8th ed. New York: McGraw-Hill; 2010.

5. Niewold T,Bundrick J. Disseminated Intravascular Coagulation due to Cytomegalovirus Infection in an Immunocompetent Adult Treated with Plasma Exchange. Am J Hematol 2006;81:454-457.

6. Tiula E, Leinikki P. Fatal cytomegalovirus infection in a previously healthy boy with myocarditis and consumption coagulopathy as presenting signs. Scand J Infect Dis 1972; 4(1):57-60.

7. Persoons M, Stals F, Van Dam-Mieras M et al. Multiple organ involvement during experimental cytomegalovirus infection is associated with disseminated vascular pathology. J Pathol 1998; 184(1):103-9.

8. Van Dam-Mieras M, Muller A, van Hinsbergh V, et al. The procoagulant response of cytomegalovirus infected endothelial cells. Thromb Haemost 1992; 68(3):364-70.

9. Orasch C,Conen A. Severe primary cytomegalovirus infection in the immunocompetent adult patient: a case series. Scand J Infect Dis 2012;44(12):987-91.

10.Eddleston M, Peacock S, Juniper M, et al. Severe cytomegalovirus infection in immunocompetent patients. Clin Infect Dis 1997; 24(1):52-6. 